\title{
RUOLO DELL'INFEZIONE OCCULTA DA HBV NEL PAZIENTE IMMUNOCOMPROMESSO
}

Ferraro D., Giglio M., lannitto E. ${ }^{2}$, Minardi V. ${ }^{2}$, Cardinale F., Pizzillo P., Craxì A. ', Di Stefano R.

Dip di Igiene e Microbiologia,

'Dip. Biomedico di Medicina Interna e Specialistica,

${ }^{2}$ Dip di Discipline Chirurgiche e Oncologiche,

Università di Palermo.

Background. La presenza di sequenze genomiche di HBV nel fegato o nel sangue di soggetti HBsAg -vi, con o senza antiHBc e/o antiHBs, definisce una infezione occulta da $\mathrm{HBV}$, caratterizzata da forte soppressione della replicazione virale. In soggetti con malattie linfoproliferative l' immunosoppressione da chemioterapia può causare una derepressione dell'HBV con manifestazioni cliniche che simulano una epatite acuta de novo.

\section{Obiettivo.}

Analizzare la frequenza di infezione occulta da HBV in pazienti emopatici in chemioterapia, e caratterizzare il profilo virologico della riattivazione virale.

\section{Pazienti e metodi.}

92 pazienti con malattie oncoematologiche, osservati presso una singola UO fra il 1998 ed il 2005, sono stati classificati in tre gruppi: HBV naïves (HBsAg, antiHBc, anti-HBs -vi), HBV experienced (HBsAg -vo, anti-HBc e/o antiHBs +vo), HBsAg +vi. Su un campione di sangue periferico, prelevato prima dell'inizio della chemioterapia, è stata effettuata la ricerca di HBV-DNA con una nested PCR home made specifica per le quattro ORF del genoma virale.

Risultati e conclusioni.

32 soggetti erano HBV naïves, $42 \mathrm{HBV}$ experienced e 18 HBsAg positivi (mediana HBV-DNA 9x104/ml). Una infezione occulta da HBV era rilevabile nel $20 \%$ dei pazienti. Undici fra i pazienti HBsAg -vi sono divenuti HBsAg +vi durante la chemioterapia e HBV-DNA +vi (mediana HBVDNA 40x10 $)$. La comparsa di HBsAg e HBV-DNA si associava ad una epatite acuta con ALT $>10$ volte la norma e l'HBeAg compariva in 9 pazienti. In 5 degli 11 pazienti era presente HBV-DNA sierico al baseline.

La riattivazione di una infezione occulta da HBV è un evento frequente nei pazienti oncoematologici in aree a pregressa alta endemicità di HBV.

Uno screening mediante ricerca di HBV-DNA con un test ad elevata sensibilità e specificità consente di individuare $\mathrm{i}$ soggetti potenzialmente a rischio di riattivazione e di mettere in opera una profilassi preemptive con analoghi nucleosidici. 